\title{
Reflexões iniciais sobre as interações pais/cuidadores-criança no contexto da Covid-19
}

\author{
Initial theoretical reflections on parent/caregiver-child interactions in the context of Covid-19
}

\author{
Cristiane Ajnamei dos Santos Alfaya* $\bullet$
}

Universidade Federal do Recôncavo da Bahia, Cetro de Ciências da Saúde, Santo Antonio de Jesus, Bahia, Brasil. *Autor para correspondência. E-mail: cristianealfaya@gmail.com

\section{Ponto de vista}

Palavras-chave: desenvolvimento, cuidados, infância.

Os estudos sobre a influência dos cuidados pais-bebê no desenvolvimento socioemocional da criança tiveram início com a observação direta dos comportamentos interativos desde a década de 40 , a partir das descrições de teóricos do desenvolvimento como René Spitz e Anna Freud com crianças separadas de seus pais em instituições e sob condições de guerra. Os estudos de observação realizados nessas condições de separação, em que a mãe não estava presente para atender a criança, indicaram a natureza da dependência infantil e a importância dos comportamentos de cuidado para o desenvolvimento da criança. Os resultados de estudos indicando sofrimento psíquico como resultante da falta de cuidado incentivaram novos estudos acerca dos comportamentos de cuidado, entre os quais se pode citar autores como Winnicott (2000), Mahler et al. (2002) and Bowlby (1989). Estes estudiosos admitiram a fundamental importância dos primeiros comportamentos de cuidado, em especial a qualidade das características do vínculo afetivo com os cuidadores principais, para o desenvolvimento emocional da criança (Brazelton \& Cramer, 1992).

Mais recentemente, o conceito de regulação emocional é definido a partir da experiência emocional e da expressão das emoções (Eisenberg, 1998). Atualmente, este conceito é estudado por estudiosos interessados em conhecer as diferentes maneiras pelas quais a criança regula as suas emoções e os seus comportamentos emocionalmente direcionados, considerando o sentimento de capacidade e o ajustamento social. Eisenberg indica os meios pelos quais a criança se auto-regula: 1) rotinas de cuidados; 2) estimulação do ambiente; 3) apoio do ambiente na organização das experiências da criança. Eisenberg também indica três tipos de regulação da criança: 1) estados internos de sentimentos e emoções; 2) modulação das expressões comportamentais de impulsos e sentimentos; 3) organização, solução de problemas e previsão de manejo nas situações, com o objetivo de diminuir o estresse e emoções negativas. Sendo assim, o estabelecimento da auto-regulação da criança é influenciado tanto por fatores externos como internos (Eisenberg, 1998).

No tocante aos fatores externos, a capacidade de pais/cuidadores contribuir para a regulação do estado afetivo da criança envolve o estado emocional da própria pessoa que exerce a função de cuidar, a representação que ela tem da criança, a história de vida dela com seus cuidadores, e a apreensão que ela faz das mensagens de afeto da criança nas trocas interativas. É através de comportamentos contingentes dos pais/cuidadores em relação aos comportamentos da criança, considerando a maneira como responde, que será definida parte importante do processo de regulação emocional da criança. Sendo assim, a capacidade da criança de organizar as suas comunicações afetivas depende da qualidade da regulação mútua nas interações entre a criança e seus pais/cuidadores (Tronick, 1989).

Quando a criança é privada de aprender a como regular a sua atenção e as suas emoções devido à falta de comportamentos contingentes e pouca sensibilidade do ambiente (pais/cuidadores), o seu desenvolvimento socioafetivo e cognitivo pode ficar comprometido.

Sendo assim, a participação dos cuidadores no desenvolvimento da criança é enfatizada por Brazelton e Cramer (1992), ao elucidarem sobre o desenvolvimento dos comportamentos de autonomia, que ocorre por volta dos primeiros seis meses de vida do bebê. Neste período de vida, o sentido de competência e de controle voluntário é estimulado quando o cuidador é capaz de permitir ou mesmo encorajar o bebê em seus comportamentos, facilitando o desenvolvimento da autonomia. A criança começa a inventar jogos para colocar o apego dos pais à prova, sintonizando-os e dessintonizando-os, tomando iniciativa nas brincadeiras 
e direcionando a interação. O controle sobre a atenção dos cuidadores permite que o bebê comece a se separar e a se tornar independente.

Os mesmos autores destacam a sincronia, simetria, contingência, encadeamento, brincadeira e autonomia como características fundamentais das relações iniciais entre pais-bebê para o desenvolvimento da criança. No que se refere aos comportamentos de sincronia, a criança precisa aprender a regular uma variedade de sistemas fisiológicos a fim de conseguir investir a sua atenção aos estímulos do ambiente. Os cuidadores adquirem fundamental importância para a criança desenvolver a sincronia, quando ajustam o seu comportamento aos comportamentos da criança, auxiliando na regulação e controle das respostas motoras que interferem na capacidade de prestar atenção. A criança, quando engajada a uma troca interativa sincrônica, aprende que os pais/cuidadores podem ser confiáveis, sendo capaz de participar mais ativamente. A simetria e a contingência demandam dos pais/cuidadores disponibilidade cognitiva e emocional. O ambiente responde de modo contingente quando consegue decodificar as mensagens transmitidas pelos sinais da criança (expressões verbais e não verbais). A capacidade do bebê de realizar comportamentos de sinalização é contingente em relação à sua habilidade de auto-regulação, que por sua vez, está diretamente relacionada com a capacidade dos pais/cuidadores regularem as suas respostas ao bebê. Tendo compreendido as necessidades um do outro, estabelecem um ritmo que se assemelha a um conjunto de regras. Cada membro da díade encadeia o comportamento do outro, estabelecendo o ritmo de atenção e desatenção, o qual já vinha sendo construído por meio da sincronia. Com isso, a interação apresenta um envolvimento maior, pois os membros da díade se adaptam um ao outro a ponto de a criança não se limitar a seguir as sinalizações do parceiro, mas de modo que os ritmos dos pais/cuidadores tendam a corresponder aos comportamentos do bebê. $\mathrm{O}$ encadeamento permite que tanto a criança como o cuidador controlem o aumento, a diminuição e a manutenção da intensidade do nível do diálogo. Nesse diálogo, enquanto o bebê aprende sobre si mesmo, os pais/cuidadores descobrem maneiras de manter a atenção da criança e de levá-la a ampliar o próprio repertório (Brazelton \& Cramer, 1992).

Na medida que a sincronia, o encadeamento e as respostas contingentes do ambiente reforçam capacidades diferentes, a criança percebe que é capaz de controlar a interação. Por volta de cinco meses de vida, as crianças começam a controlar o comportamento do ambiente por meio de sua capacidade de iniciar e interromper a interação. Na perspectiva interacional, o comportamento exploratório da criança nasce da certeza da emissão de respostas previsíveis do ambiente. Neste período de vida, o comportamento autônomo por parte da criança é sinal de um relacionamento saudável e sua ausência, uma possível simbiose, e dificuldade de apego. A relação primordial entre pais/cuidadores-bebê promove o desenvolvimento do apego e a exploração do ambiente através do sentido de previsibilidade contido na sincronia, simetria, contingência e encadeamento. Dessa forma, o comportamento exploratório da criança envolve os processos interativos na díade pais/cuidadores-bebê, sobretudo a regulação emocional, a regulação do comportamento emocionalmente direcionado, e a regulação ou gerenciamento na situação de estresse da criança, evocado pela estimulação emocional do ambiente.

Desde o final do ano de 2019, a população mundial vivencia um clima emocional caracterizado pela angústia, ansiedade e medo da morte, causado pelo SARS-CoV-2. Devido morbimortalidade e imprevisibilidade do vírus, bem como o impacto direto nas questões econômico-sociais, os anseios e preocupações, favoreceram o aumento dos quadros de depressão na população (Afonso, 2020; Sadock et al., 2016).

Os comportamentos de baixa contingência e de sensibilidade podem ser observados em casos de depressão pós-parto. A literatura científica tem compreendido a relação entre a depressão e o desenvolvimento infantil, a partir da falta de respostas contingentes em que a criança é privada de aprender a como regular a sua atenção e as suas emoções. As dificuldades cognitivas de crianças de mães com indicadores de depressão são investigadas no contexto da relação de apego, quando este, geralmente, é estabelecido de maneira insegura devido à falta de contingência (Hay, 1997).

As mães com indicadores de depressão pós-parto, geralmente, respondam aos seus bebês mais lentamente às solicitações e expressões da criança. As crianças, além de receberem poucos estímulos contingentes de suas mães, também tendem a apresentar um afeto não regulado, caracterizado pelo predomínio de expressões negativas de afeto, que pode ser observado nas demais interações sociais. $\mathrm{O}$ afeto não regulado na criança pode prejudicar o aprendizado, uma vez que a capacidade de processar as informações é inadequada (Murray, 1992; Hay, 1997).

Existe concordância sobre a possibilidade de influências negativas da depressão em mães e a regulação emocional infantil. As mães com depressão, dificilmente, serão capazes de promover um modelo positivo de expressão emocional e facilitar a regulação emocional da criança, devido pouca responsividade. A criança com 
dificuldade para regular os seus afetos, sentimentos e atenção, devido aos comportamentos maternos de intrusividade, pouca responsividade e a baixa sensibilidade, considerando a falta de contingências, poderá elaborar um modelo interno de funcionamento inseguro. Dessa forma, a criança poderá se comportar de maneira ansiosa, resistente ou evitadora ao se sentir insegura e pouco confiante para explorar o ambiente, o que pode dificultar o desenvolvimento de sua autonomia e independência (Goodman \& Gotlib, 2002).

Considerando a necessidade de comportamentos responsivos e contingentes por parte dos pais/cuidadores envolvendo a estabilidade emocional no sentido de auxiliar na promoção do desenvolvimento cognitivo e socioemocional da criança, o aumento do número de casos de pessoas com depressão em decorrência da morbimortalidade e imprevisibilidade do vírus SARS-CoV-2, justifica a reflexão teórica sobre os possíveis efeitos da pandemia no desenvolvimento infantil, a partir das interações entre pais/cuidadores-criança. Além disso, são necessários estudos empíricos descritivos e longitudinais que caracterizem as condições atuais dos comportamentos de interação pais/cuidadores-criança, bem como examinem o estado emocional dos pais e cuidadores de crianças pequenas, a fim de promover estratégias de intervenção, o mais breve possível. Sendo assim, o presente estudo sugere a realização de estudos empíricos com o objetivo de avaliar a regulação emocional da criança e de seus pais/cuidadores; investigar o sentido de competência e controle o voluntário do bebê, a partir da observação dos comportamentos de encorajamento e permissividade dos pais/cuidadores; e examinar os comportamentos de autonomia da criança em casos de mães com e sem depressão no contexto da Covid-19.

\section{Referências}

Afonso, P. 2020. O impacto da Pandemia do COVID-19 na Saúde Mental. Acta Médica Portuguesa, 33(5), 351358.

Bowlby, J. 1989. Uma base segura: aplicações clínicas da teoria do apego. Porto Alegre: Artes Médicas

Brazelton, T., \& Cramer, B. 1992. As primeiras relações. São Paulo: Martins Fontes.

Eisenberg, N. 1998. Introduction. In: W. Damon, \& N. Eisenberg (Orgs.). Handbook of child psychology: social, emotional and personality development (pp. 1-24). Texas: John Wiley \& Sons, Inc.

Goodman, S., \& Gotlib, I. 2002. Transmission of risk to children of depressed parents: integrations and conclusions. In: S. Goodman, \& I. Gotlib (Orgs.). Children of depressed parents: Mechanisms of risk and implications for treatment (pp. 307-326). American Psychological Association.

Hay, D. 1997. Postpartum depression and cognitive development. In: L. Murray, \& P. Cooper (Orgs.). Postpartum depression and child development (pp. 85-110). New York: Guilford Press.

Mahler, M. S., Pine, F., \& Bergman, A. 2002. O nascimento psicológico da criança: simbiose e individuação. Porto Alegre: Artes Médicas.

Murray, L. 1992. The impact of postnatal depression on infant development. Journal of Child Psychology and Psychiatry, 33(3), 543-561.

Sadock, B. J., Sadock, V. A., \& Ruiz, P. 2016. Compêndio de psiquiatria: ciência do comportamento e psiquiatria clínica $\left(11^{\mathrm{a}}\right.$ ed.). Porto Alegre: Artmed.

Tronick, E. Z. 1989. Emotions and emotional communication in infants. American Psychologist, 44, 112-119.

Winnicott, D. 2000. Da pediatria a psicanálise. São Paulo, SP: Imago.

\section{Minicurrículo}

Cristiane Ajnamei dos Santos Alfaya. Graduação em Psicologia (PUCRS); Mestre em Psicologia Clínica (PUCRS); Doutora em Psicologia do Desenvolvimento (UFRGS).

Como citar: Alfaya, C. A. S. 2021. Reflexões iniciais sobre as interações pais/cuidadorescriança no contexto da Covid-19. Pubsaúde, 8, a284. DOI: https://dx.doi.org/10.31533/pubsaude8.a284

Recebido: 11 nov. 2021.

Revisado e aceito: 11 nov. 2021.

Conflito de interesse: a autora declara, em relação aos produtos e companhias descritos nesse artigo, não ter interesses associativos, comerciais, de propriedade ou financeiros que representem conflito de interesse.

Licenciamento: Este artigo é publicado na modalidade Acesso Aberto sob a licença Creative Commons Atribuição 4.0 (CC-BY 4.0). 